\title{
A Study on Development of Balanced Scorecard for Management Evaluation Using Multiple Attribute Decision Making
}

\author{
Kwang Mo Yang ${ }^{1}$, Young Wook $\mathrm{Cho}^{2}$, Seung Hee $\mathrm{Choi}^{3}$, Jae Hyun Park ${ }^{4}$, Kyoung Sik Kang \\ ${ }^{1}$ Department of Industrial Engineering, Yuhan University, Puchoen, Korea; ${ }^{2}$ Department of Technology \& Systems Management, Induk \\ Institute of Technology, Seoul, Korea; ${ }^{3}$ Department of Industrial \& Manufacturing Engineering, Pennsylvania State University, Penn- \\ sylvania, USA.; ${ }^{4}$ Department of Qualification Trend Analysis, Human Resource Development Service, Seoul, Korea; ${ }^{5}$ Department of \\ Industrial \& Management Engineering, Myongji University, Yongin, Korea. \\ Email: kmyang@yuhan.ac.kr
}

Received September 22 $2^{\text {nd }}, 2009$; revised October 12 $2^{\text {th }}, 2009$; accepted October $20^{\text {th }}, 2009$.

\begin{abstract}
Recently, most businesses have introduced a system for improving their responsibility to the customers in terms of job improvement. For example, small-quantity batch production increases cost but improve efficiency of management. Companies have been introduced the balanced scorecard to evaluate their management as part of improvement, while they suffer from many trials and errors. Many businesses still have difficulty in introducing balance scorecard concept in their process, but we suggest a method to successfully introduce the balance scorecard. This study aims to suggest a new performance measurement model reflecting relative importance of the key performance indicators for each factor. Our model is applied to several companies in real-world to validate the new model. Also, our study proposes a methodology for an adequate performance measurement using multiple attribute decision making.
\end{abstract}

Keywords: Balanced Scorecard, Multiple Attribute Decision Making, Management Evaluation

\section{Introduction}

A large number of small and medium enterprises have realized it is necessary to employ a management evaluation system for increasing competitiveness, renovating their business system, and decreasing the cost. Unfortunately, the efforts and investment on the system do not seem to lead to the output. Consequently, it is necessary to develop a new methodology for efficient implementation and maintenance of a management evaluation system for reflecting both the department objective and the entire business goal. Balanced Scorecard (BSC) is a deliberately selected balanced set of measures derived from the vision and strategies that represent a tool for leaders to use in communicating strategies to the organization and motivating change [1]. Multiple attribute decision making (MADM) is one of the decision making methods to choose the alternative under multiple attributes [2]. If the BSC measuring achievement is applied to MAMD, a business could consider each attribute based on not the each department, but the vision and strategy of the entire business. Thus, this paper will suggest the method using BSC enabling to evaluate a management for insuring productivity in the real MAMD problem including more alternatives and attribute.

\section{Related Work}

\subsection{Balanced Scorecard (BSC)}

The current business environment is an era of megacompetition absolutely requiring a great measurement process and an excellent management method of administration performance. Measurement is a key factor in management. Kaplan and Norton [1] emphasized that the importance of performance measure by saying "You cannot control what you cannot measure." Balanced Scorecard is a deliberately selected balanced set of measures derived from the vision and strategies that represent a tool for leaders to use in communicating strategies to the organization and motivating change [1]. The concept of performance measure is accepted by private companies, first, and then, it has been spread to public institutions and non-profit organizations. The performance measurement system was traditionally limited to appearance emphasizing and growth-oriented aspects and financial measurement factors. However, the performance measure- 
ment of an organization based on financial factors has showed a limitation as a means for delivering information on the quality and performance of administration. Many researchers have studied performance measurement based on financial factors to overcome the limitation. Currently, many companies have noted the BSC proposed by Kaplan and Norton [1] and have gradually applied and operated the BSC. For example, the research on the administration performance measurement method and management has been studied, actively, and there were remarkable development. However, the applied area is still limited to human resource organization. In this study, we estimate the weight reflecting the adequate importance of the BSC for lower Key Performance Indicators (KPI) (Figure 1) by using a Multiple Attribute Decision Making (MADM) based on the analysis of administration environments of company. In other words, we consider the weight reflecting practical features and suggest a desirable performance measurement model based on the weight. This study aims to suggest a new performance measurement model reflecting relative importance for the KPI for each aspect and apply the new performance measurement model to real business environment to validate the effect of the new model, identify any limitation, and suggest a methodology for proper performance measurement.

\subsection{Multiple Attribute Decision Making (MADM)}

Multiple attribute decision making (MADM) is one of the decision making methods to choose the alternative under multiple attributes [3]. An MADM problem could occur when we understand the management situation. Since a number of conflict factors are caused by the limited resources, MADM allows a decision maker to determine the factor among the variables with multi-attribute or the optimal environment to operation situation. To solve an MADM problem with a numerical approach, Barron and Schmidt [4] attempted to solve a problem with distance or fuzzy index. Dyer and Sarin [5], French [6], Haimes and Chankong et al. [7] suggested the interactive approach to improve the method using multiobjective liner programming. However, it was hard to keep the consistency and to guarantee the optimal solution. Analytic Hierarchy Process (AHP) [8,9] and Elimination Et Choice Translating Reality(ELECTRE) [10] became more complicated because the more attributes, the more coefficient by geometric progression. Cho [3] described the method to determine the optimal plant in the MADM problem having mixed attributes, such as nominal-the-better type, smaller-the-better type, and larger-the-better type. Although the method can not only decide the optimal plant but also solve the MADM having mixed attributes, it is possible only if each attribute is independent. In this paper, we put the priority on the management variables having the high mean value and the low difference of the weights of a certain factor by experts to understand management situation with Process Capability Index. Thus, we will suggest the method using BSC enabling to evaluate a management for insuring productivity in a real MADM problem including more alternatives and attributes.

\section{Management Evaluation Formula}

Management evaluation method is based on balanced scorecard with multiple attribute. It is consider the subjective and objective attributes (Figure 2). The objective attributes are the element calculated with the target data and real data observed. The subjective attributes are the sub variables under the basic four aspects in the BSC.

The $v$ is defined as decision making matrix, having each

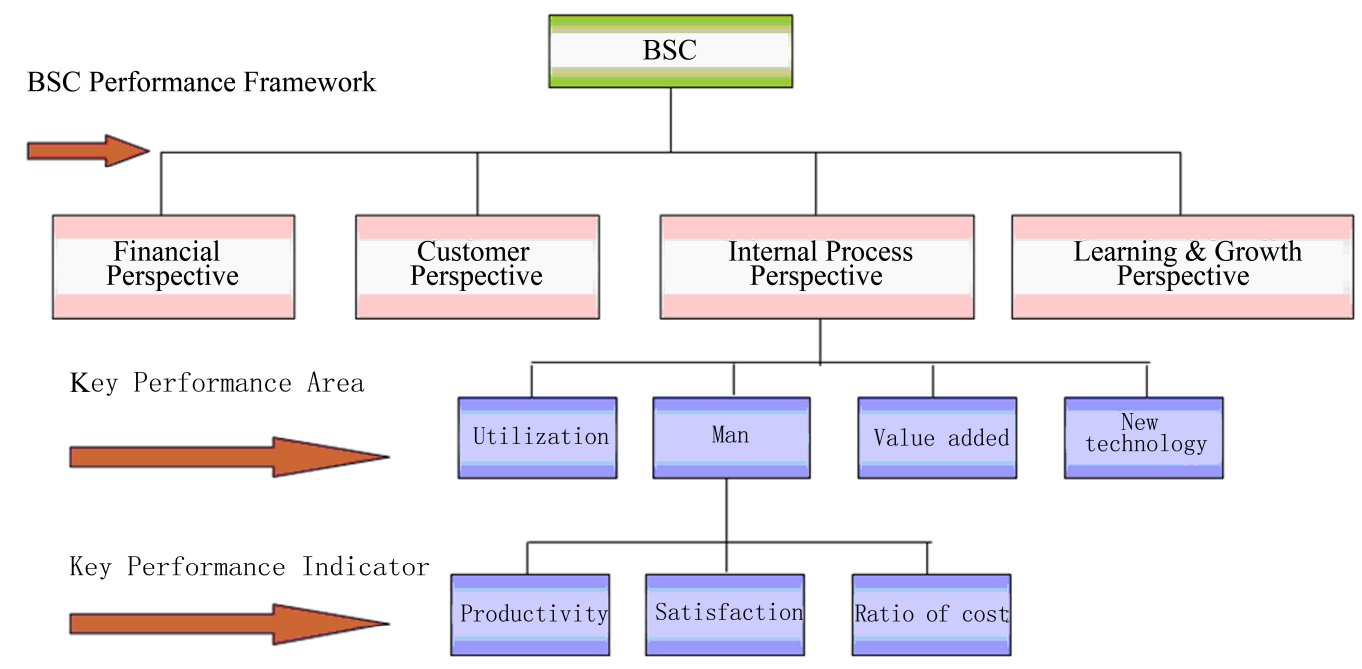

Figure 1. Example of KPI and four aspects of the BSC 
(1) Subjective Attribute

(2) Objective Attribute

\begin{tabular}{|c|c|c|c|c|c|c|c|c|c|c|c|c|}
\hline \multirow{2}{*}{$\begin{array}{c}\text { four } \\
\text { aspects }\end{array}$} & \multirow{2}{*}{$\begin{array}{c}\text { Sub } \\
\text { Variables }\end{array}$} & \multirow{2}{*}{$\begin{array}{c}\text { Target } \\
\text { Data } \\
\end{array}$} & \multirow{2}{*}{$\begin{array}{r}\text { Red } \\
\text { Data } \\
\end{array}$} & \multicolumn{9}{|c|}{ Class (Real Data/Target Data) } \\
\hline & & & & -40 & -50 & -60 & -70 & -80 & -90 & -100 & -110 & 120 \\
\hline \multirow{4}{*}{$\begin{array}{l}\text { financial } \\
\text { aspect } \\
\text { (F) }\end{array}$} & F1 & & & & & & & & & & & \\
\hline & $\mathrm{F} 2$ & & & & & & & & & & & \\
\hline & : & & & & & & & & & & & \\
\hline & Fn & & & & & & & & & & & \\
\hline \multirow{4}{*}{$\begin{array}{l}\text { customer } \\
\text { aspect } \\
\text { (C) }\end{array}$} & $\mathrm{C} 1$ & & & & & & & & & & & \\
\hline & $\mathrm{C} 2$ & & & & & & & & & & & \\
\hline & & & & & & & & & & & & \\
\hline & $\mathrm{Cn}$ & & & & & & & & & & & \\
\hline \multirow{4}{*}{$\begin{array}{l}\text { process } \\
\text { aspect } \\
\text { (P) }\end{array}$} & P1 & & & & & & & & & & & \\
\hline & P2 & & & & & & & & & & & \\
\hline & : & & & & & & & & & & & \\
\hline & Pn & & & & & & & & & & & \\
\hline \multirow{4}{*}{$\begin{array}{l}\text { learning } \\
\text { aspect } \\
\text { (L) }\end{array}$} & L1 & & & & & & & & & & & \\
\hline & $\mathrm{L} 2$ & & & & & & & & & & & \\
\hline & $:$ & & & & & & & & & & & \\
\hline & Ln & & & & & & & & & & & \\
\hline
\end{tabular}

Figure 2. BSC checklist form (per department)

department of $m$ and reconsideration attribute of $l$ connected with this as following:

$$
\begin{aligned}
& \begin{array}{llllll}
X_{1} & X_{2} & \cdots & X_{j} & \cdots & X_{l}
\end{array} \\
& v=\begin{array}{c}
A_{1} \\
A_{2} \\
\vdots \\
A_{i} \\
\vdots \\
A_{m}
\end{array}\left[\begin{array}{cccccc}
x_{11} & x_{12} & \cdots & x_{1 j} & \cdots & x_{1 l} \\
x_{21} & x_{22} & \cdots & x_{2 j} & \cdots & x_{2 l} \\
\vdots & \vdots & \vdots & \vdots & \vdots & \vdots \\
x_{i 1} & x_{i 2} & \cdots & x_{i j} & \cdots & x_{i l} \\
\vdots & \vdots & \vdots & \vdots & \vdots & \vdots \\
x_{m 1} & x_{m 2} & \cdots & x_{m j} & \cdots & x_{m l l}
\end{array}\right]
\end{aligned}
$$

where, $A_{i}=i$ th department, $X_{j}=j$ th attribute, $x_{i j}=$ evaluation value $X_{j}$ of for attribute in department $A_{i}$.

\subsection{Subjective Attribute Formula}

\subsubsection{Weighted Decision to Each Subjective Attribute}

It is very difficult to assign the weight to each attribute in an MADM problem. Since last selection crystallization can change according to the weight given, the weight should be assigned, deliberately. In this paper, we decide the weight based on the suggestion of experts, and the method determining the weight could be used for process capacity index. Process capability is the process characteristic ability that reflects how identical product can be produce according to manufacturing process established in product design process, which means uniformity of the product. To estimate characteristic ability, various statistical methods have suggested. Evaluating process capacity by variables of process and specification limit of product is known as process capacity analysis, and the process capacity analysis can be expressed in terms of process capability index $\left(\mathrm{C}_{\mathrm{p}}\right)$. The process capability index is developed based on the concept of $6 \sigma$ and applied first to industry field.

$$
C_{\mathrm{p}}=\frac{U S L-L S L}{6 \sigma}=\frac{T}{6 \sigma}
$$

For a single specification, the limit is defined as following.

For an upper specification, the limit is:

$$
C_{p}=\frac{U S L-\mu}{3 \sigma}
$$

For a lower specification, the limit is:

$$
C_{p}=\frac{\mu-L S L}{3 \sigma}
$$

In this paper, we will use the process capability index for a lower specification limit only. The weight for each attribute is assigned by the data that several experts decide to each attribute. The evaluation data of experts for each attribute is determined by experts scoring from 9 to 1 . The mean of data $(\mu)$ that experts decide can be calculated. The lower specification limit is 1 that experts decided absolute minimum, and the standard deviation that each expert decides is $\sigma$ which is following.

$$
\hat{\sigma}=s=\sqrt{\frac{\sum\left(b_{j p} \bar{b}\right)^{2}}{n-1}} \quad(\mathrm{p}=1,2, \ldots ., \mathrm{n})
$$

where, $b_{j p}$ is the mean that expert $P$ decided data for each attribute $j$. And then, in this paper, we put the priority order on the attribute $X_{j}$ having the high mean value and the low difference of the weights by the decision of experts. The values decided by experts are calculated by 
Equation (4), normalized by Equation (5), and represented as $N C_{p}$ (Normalized Capability Index).

$$
N P_{p j}=\frac{C_{p j}}{\left(C_{p 1}+C_{p 2}+\ldots . . C_{p i}\right)}
$$

$N C_{p}$ is defined the weight for each attribute, and the notation is replaced to $w$, where, $w$ is under a certain criterion, such as following:

$$
\begin{gathered}
w=w_{1}, w_{2}, \ldots . . w_{l}, \quad \sum_{j=1}^{l} w_{j}=1 \\
\text { here, } \quad w_{j}=C_{p i} / \sum_{j=1}^{l} C_{p i}
\end{gathered}
$$

\subsection{Objective Attribute Formula}

\subsubsection{Normalization of Evaluation Value Matrix for Objective Attribute}

Evaluation value $x_{i j}$ for attribute $X_{j}$ in each department $A_{i}$ is considered as profit attribute or cost attribute by normalized step, and the quantitative values of attributes are also normalized in the same intervals. For example, the profit attribute, high preference as evaluation value, is normalized as following:

$$
\begin{gathered}
r_{i j}=x_{i j} /\left(x_{1 j}+x_{2 j}+\ldots+x i_{j}+\ldots+x_{m j}\right) \\
(i=1,2, \ldots, m ; \quad j=1,2, \ldots, l)
\end{gathered}
$$

Otherwise, cost attribute, low preference as evaluation value, is normalized as following:

$$
\begin{aligned}
r_{i j}= & \left(1 / x_{i j}\right) /\left[\left(1 / x_{1 j}\right)+\left(1 / x_{2 j}\right)+\ldots+\left(1 / x i_{j}\right)+\ldots+\left(1 / x_{m j}\right)\right. \\
& (i=1,2, \ldots, m ; \quad j=1,2, \ldots, l) \\
& \text { here, } 0 \leq r_{i j} \leq 1
\end{aligned}
$$

And then, we can make matrix $\mathrm{R}$ as following based on the normalized values.

$$
R=\left[\begin{array}{cccc}
r_{11} & r_{12} & \cdots & r_{1 l} \\
r_{21} & r_{22} & \cdots & r_{2 l} \\
\vdots & \vdots & \ddots & \vdots \\
r_{m 1} & r_{m 2} & \cdots & r_{m l}
\end{array}\right]
$$

This paper presents the process of calculation only for the financial aspect factor, and the processes for the rest aspects are regarded identical. If $P R(F)_{i}$ is preference rate for department $i, P R(F)_{i}$ is weighted mean of attribute for process $i$.

$$
P R(F)_{i}=\sum_{j=1}^{l} F w_{j} \times N F(i)_{j}
$$

where,

$$
\sum_{i=1}^{m} P R(F)_{i}=1
$$

$N F(i)_{j}$ is the normalized data of department in financial attribute $j$. According to the result calculated by Equation (9) for each department, most high preference rate had department select and then if free department is department that had optimum the priority order as following:

$$
\max P R(F)_{i}=\max \left(P R(F)_{1}, P R(F)_{2}, \ldots \ldots, P R(F)_{m}\right)
$$

In this model, we assume each factor is independent each other. Similarly, the data for customer aspect, internal process aspect, and learning/growing aspect can be estimated. The proposed model has evaluated in a department performance in management environment. The result is applied to the simulated operation of CLV (Customer Lifetime Value) [11]. The primary evaluation criterion is the BSC which consists of financial aspect, customer aspect, internal process aspect, and learning/growing aspect. Also, in this paper, it will be able to be applied to MADM for deciding weigh of each variable. Therefore, we can summary the step to evaluate data for each department as following:

Step 1) The variables to assign weight are divided into financial aspect, customer aspect, internal process aspect, and learning/growing aspect.

Step 2) The data rank of each decided variable is determined by Group Consensus.

Step 3) Find sub-variables in the higher level variables. The sub-variables can be changed by the condition of the enterprise.

Step 4) Assign the weight for each factor by using MADM

Step 5) Decide total evaluation data for the department by using Equation (11).

$$
\begin{gathered}
\text { Total Evaluation Data }=a P R(F i)+\beta P R(C i) \\
+\gamma P R(P i)+\delta P R(L i)
\end{gathered}
$$

here

$$
\begin{aligned}
& 0<\alpha<1,0<\beta<1,0<\gamma<1,0<\delta<1 \\
& \alpha+\beta+\gamma+\delta=1, \\
& F_{i}>0, P_{i}>0, L_{i}>0, C_{i}>0
\end{aligned}
$$

where

$\alpha$ : financial aspest weight

$\beta$ : customer aspect weight

$\gamma$ : internal process aspect weight

$\delta$ : learning/growing aspect weight

$P R\left(F_{i}\right)$ : preference rate of financial aspect

$P R\left(C_{i}\right)$ : preference rate of customer aspect

$P R\left(P_{i}\right)$ : preference rate of internal process aspect

$P R\left(L_{i}\right)$ : preference rate of learning/growing aspect

The result in Figure 3 is drawn by applying the suggested balanced scorecard to a real company. In Figure 3, we compare the evaluation data for each aspect and show the total evaluation data. 

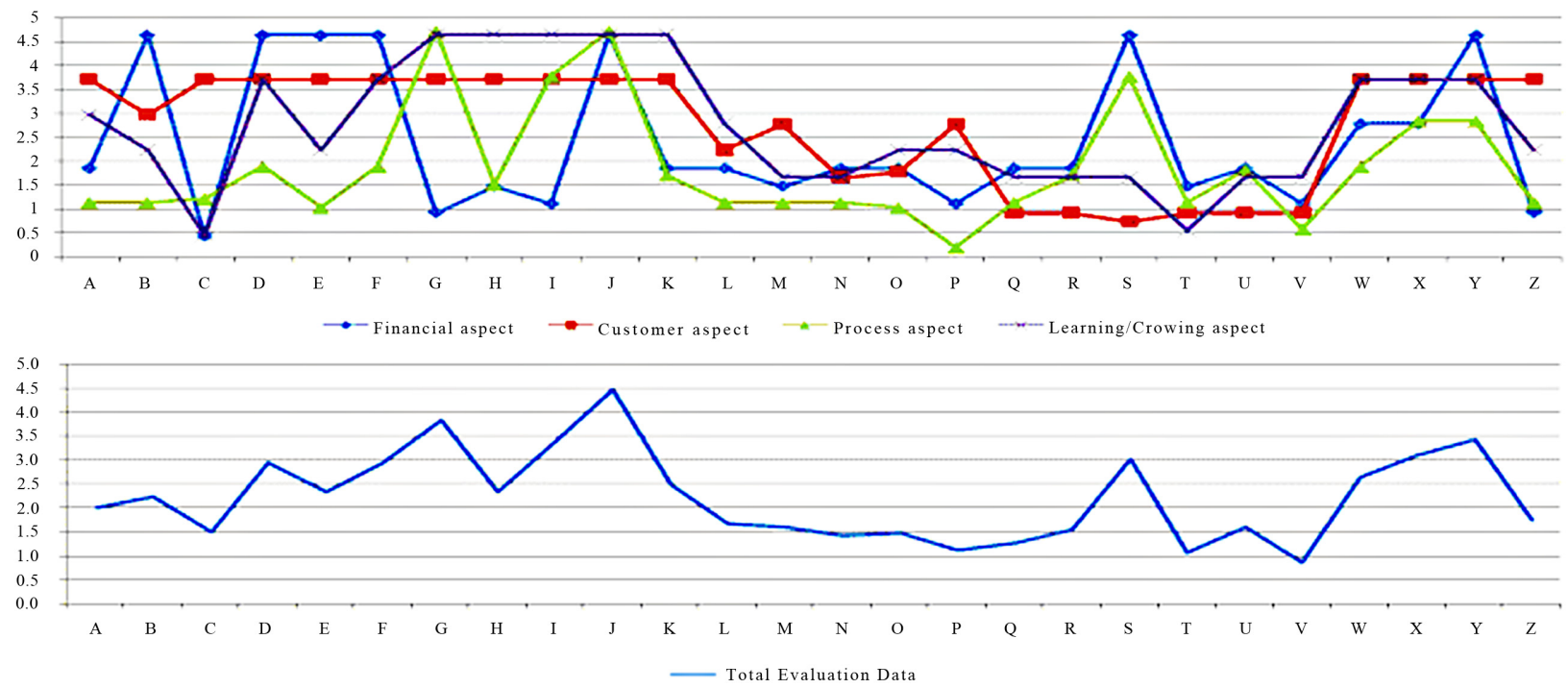

Figure 3. Result of management evaluation data for each department in a company

\section{Conclusions}

Among the methods to solve multiple attribute decision making with balanced scorecard for management evaluation for a department, numerical approaches offer the optimal solution, but fail to reflect the opinions of decision makers and CEO. Besides the current interactive approaches making up for the weak point fail to keep the consistency and to insure the optimal solution since it is hard to consider the entire alternative and attribute, simultaneously. Moreover, the increase in the number of attributes grows the amount of information due to pair wise comparison between the alternatives. In this paper, we propose the balanced scorecard method to assign the attribute weight by an expert group in the multiple attribute decision making including more alternatives and attributes. Also, we suggest the management evaluation method that assigns more weight on the attribute having the high mean weight by experts and the low difference or consensus in the evaluation. The proposed method could contribute to developing a good approach to reflecting both the optimal solution and the strategy of the entire business.

\section{REFERENCES}

[1] R. S. Kaplan and D. P. Norton, "Transforming the balanced scorecard from performance measurement to strategy," Accounting Horizons, Vol. 15, No. 2, pp. 87-104, 2001.

[2] K.-M. Yang, Y.-W. Wook, and J.-H. Park, "A study on evaluation method for process safety using multiple attribute decision making," 38th International Conference on CIE, Las Vegas, USA, pp. 2274-2278, 3-6 August 2008.
[3] Y.-W. Cho, "Selecting the optimal preferred facilities with multiple characteristics using Loss Function," Korea Safety Management \& Science, Vol. 2, No. 2, pp. 127-135, 2002.

[4] H. Barron and C. P. Schmidt, "Sensitivity analysis of additive multi-attribute value models," Operations Research, Vol. 36, pp. 122-127, 1988.

[5] J. S. Dyer and R. K. Sarin, "Measurable multi-attribute value functions," Operations Research, Vol. 27, No. 4, pp. 810-822, 1979.

[6] S. French, "Decision theory: An introduction to the mathematics of rationality," Ellis Horwood Series in Mathematics and its Applications, pp. 448, 1986.

[7] Y. Y. Haimes and V. Changkong, "Decision making with multiple objectives," Lecture Notes in Economics and Mathematical Systems, Springer-Verlag, New York, No. 242, pp. 388-399, 1985.

[8] L. C. Lawrence and C. Dong, "On the efficacy of modeling multi-attribute decision problems using AHP and Sinarchy," Eurpean Journal of Operational Research, Vol. 132, No. 1, pp. 39-49, 2001.

[9] T. L. Saaty, "A scaling method for priorities in hierarchical structures," Journal of Mathematical Psychology, Vol. 15, No. 3, pp. 234-281, 1977.

[10] P. T. Harker and L. G. Vargas, "The theory of ratio scale estimation: Saaty's analytic hierarchy process," Management Science, Vol. 33, No. 11, pp. 1383-1403, 1987.

[11] K.-M. Yang, S.-H. Choi, J.-H. Park, and K.-S. Kang, "Development of correlation weight customer lifetime value using analytic hierarchy process," 36th International Conference on CIE, Taipei, Taiwan, pp. 5461-5465, 20-23 June 2006. 